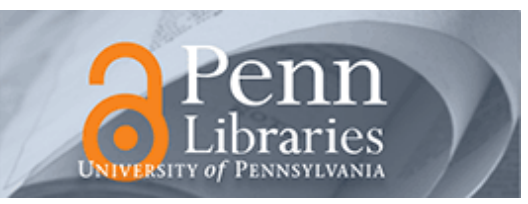

Working Papers in Educational Linguistics

(WPEL)

Volume 30

Number 1 Spring 2015

Article 1

Spring 2015

\title{
Ways of Talking (and Acting) About Language Reclamation: An Ethnographic Perspective on Learning Lenape in Pennsylvania
}

Nancy H. Hornberger

University of Pennsylvania

Haley De Korne

University of Pennsylvania

Miranda Weinberg

University of Pennsylvania

Follow this and additional works at: https://repository.upenn.edu/wpel

Part of the Education Commons, and the Linguistics Commons

\section{Recommended Citation}

Hornberger, N. H., De Korne, H., \& Weinberg, M. (2015). Ways of Talking (and Acting) About Language Reclamation: An Ethnographic Perspective on Learning Lenape in Pennsylvania. 30 (1), Retrieved from https://repository.upenn.edu/wpel/vol30/iss $1 / 1$

This paper is posted at ScholarlyCommons. https://repository.upenn.edu/wpel/vol30/iss1/1

For more information, please contact repository@pobox.upenn.edu. 


\title{
Ways of Talking (and Acting) About Language Reclamation: An Ethnographic Perspective on Learning Lenape in Pennsylvania
}

\author{
Abstract \\ The experiences of a community of people learning and teaching Lenape in Pennsylvania provide insights \\ into the complexities of current ways of talking and acting about language reclamation. We illustrate how \\ Native and non-Native participants in a university-based Indigenous language class constructed \\ language, identity, and place in nuanced ways that, although influenced by essentializing discourses of \\ language endangerment, are largely pluralist and reflexive. Rather than counting and conserving fixed \\ languages, the actors in this study focus on locally appropriate language education, undertaken with \\ participatory classroom discourses and practices. We argue that locally responsible, participatory \\ educational responses to language endangerment such as this, although still rare in formal higher \\ education, offer a promising direction in which to invest resources.
}




\title{
Ways of Talking (and Acting) About Language Reclamation: An Ethnographic Perspective on Learning Lenape in Pennsylvania
}

\author{
Nancy H. Hornberger \\ University of Pennsylvania \\ Haley De Korne \\ University of Pennsylvania \\ Miranda Weinberg \\ University of Pennsylvania
}

The experiences of a community of people learning and teaching Lenape in Pennsylvania provide insights into the complexities of current ways of talking and acting about language reclamation. We illustrate how Native and non-Native participants in a university-based Indigenous language class constructed language, identity, and place in nuanced ways that, although influenced by essentializing discourses of language endangerment, are largely pluralist and reflexive. Rather than counting and conserving fixed languages, the actors in this study focus on locally appropriate language education, undertaken with participatory classroom discourses and practices. We argue that locally responsible, participatory educational responses to language endangerment such as this, although still rare in formal higher education, offer a promising direction in which to invest resources.

\section{Alemawakan: ${ }^{1}$ Introduction}

I would support anyone taking any language class...whether or not you get very far in the language. You get a different viewpoint, it changes how you think about things. Especially if you have the chance to take an endangered language...I can't imagine anyone trying to do a language class of an endangered language without getting into the culture side and the issues involved with the fact that this is an endangered language... And I think it's very valuable, so few people think about those issues. (Interview 6/8/2012) 


\section{WPEL Volume 30, Number 1}

$\mathrm{H}$ elen described these valuable learning outcomes of endangered language education when we asked her to reflect on her experience studying Lenape language as an undergraduate. Drawing on interviews and classroom observation, this paper examines the experiences of a community of peopleincluding Helen and others, only some of whom claim an Indigenous identityengaged in learning and teaching Lenape in the Swarthmore College Linguistics department. ${ }^{2}$ We discuss the insights that this case provides into the practices and discourses of language reclamation. Specifically, we analyze ways of talking and acting about language, identity, and place that emerge in this context, and argue for the benefits of a participatory educational approach in working to achieve the goals of language reclamation.

The experience explored in this paper, where an Indigenous language is taught for communicative rather than descriptive or analytical purposes within a Linguistics department in the United States, forms part of a wider project to change the status of minoritized languages by increasing speakers and domains of use (e.g., Fishman, 1991; Hinton \& Hale, 2001; Hornberger, 2008), resisting the trend of decreased use of Indigenous languages under the assimilatory pressure of colonization. This larger project encompasses diverse actions and actors, including local efforts to increase intergenerational transmission and educational endeavors from local to national scales (e.g., Hornberger, 2008). Of the many semi-overlapping terms used to describe this project, among the most common are language revitalization (increasing numbers of speakers and domains of use) and reversing language shift (including reinstating intergenerational transmission in the home; Fishman, 1991; see also Romaine, 2006). ${ }^{3}$ In this paper we use the term language reclamation to mean not so much bringing a language back but rather bringing it forward to new uses and new users (Hornberger \& King, 1996), including claiming the "right to speak a language and to set associated goals in response to community needs and perspectives" (Leonard, 2012, p. 359).

Our case study of a Lenape language class illuminates the diverse actors, discourses and practices involved in language reclamation, as well as the continued constraints and opportunities that characterize the evolving relationship between colonial-origin institutions ${ }^{4}$ and Indigenous people. While acknowledging that not all Indigenous communities are interested in teaching their language to outsiders, or doing so in a higher education setting, we argue that in this case, and potentially others, the possible benefits of creating collaborative Indigenous language learning spaces far outweigh the risks. As Dobrin, Austin, and Nathan (2007) note, "while emotionally and morally compelling, [language endangerment] discourse has given linguists a motive for responding to the issue of language endangerment while providing little guidance on the form that response should take" (p. 5). The response of actors in this study focuses on locally appropriate language education, undertaken collaboratively. We hope that such approaches, although currently rare in our colonial-origin institutions, may be within reach elsewhere. A locally responsible, participatory educational response to the complex issue

\footnotetext{
${ }^{2}$ We use real names of institutions and some participants, with their permission and encouragement.

3 Other terms include language regenesis (McCarty, 2013), regeneration (Hohepa, 2006), reawakening (Amery, 1995) or reviving (Dorian, 1994) (bringing a dormant language back into use).

4 That is, institutions founded by non-Indigenous people during or after the colonial periode.g., federal, state, local governments, universities, churches, and schools.
} 
of the minoritization of Indigenous languages in post-colonial contexts offers a promising direction in which to invest resources.

In what follows, we refer to ways of talking (and acting) about, or discourses, as we discuss the words, actions and underlying ideologies with which people reference and recognize (Indigenous) language, identity, and place. We begin with a review of the endangerment and reclamation of minoritized Indigenous North American languages and some of the principal ways of talking and acting in this domain, followed by a brief description of the setting, participants, and methods of the present study. The body of the paper takes up the ways of talking about language, identity and place that emerged in the class, and we close with reflections on the positive potential of participatory practices of language reclamation.

\section{Awenhakei Lixsewakana: ${ }^{5}$}

\section{Ways of Talking (and Acting) About Indigenous North American languages}

Indigenous North American languages have been framed variously since European colonization of the continent began in the 15th century. From a threat in need of extermination and assimilation (e.g., US Congress, 1868), to a right within Indigenous communities (e.g., Native American Language Act, 1990, 1992), and a resource of global intellectual heritage (e.g., Smithsonian Institute Recovering Voices Initiative, 2009), colonial-origin institutions have at times obscured and at other times celebrated the existence of the hundreds of ways of communicating that originated in the territory now called North America. The history of colonial-Indigenous relations provides ample illustration of Ruíz's (1984) categorization of languages framed as problems, rights, or resources at different times, in different places, and by different actors. The colonial and post-colonial governments of the United States viewed Indigenous languages as a problem, and pursued the extermination of Indigenous languages through formal education during the 19 th and 20 th centuries. An example of the official government attitude towards Indigenous languages comes from the boarding schools that Indigenous children were required to attend (the first of which was located in Carlisle, Pennsylvania), which held an educational strategy of "Kill the Indian... and save the man"(Pratt, 1892, cited in Crawford 2007). The impacts of the abusive boarding school era are still widely felt in Native communities, including negative attitudes towards Indigenous languages and formal schooling (Battiste \& Henderson, 2000; Reyhner \& Eder, 2006).

In comparison, the impact of research on Indigenous communities and languages appears less violent. Linguists have viewed Indigenous languages as resources in their work, with an emphasis on cataloguing, archiving and comparing languages around the world (Boas, 1911; Sapir, 1912). Nevertheless, linguistic disciplinary practices may have unintended results; documentary linguistics has been critiqued as being ideologically hegemonic, resulting in control of speakers through counting, classifying, and defining their speech as a language or dialect, and associating it with a bounded territory or ethnic group (Calvet, 1974; Dobrin, Austin \& Nathan, 2007; Moore, Pietikäinen \& Blommaert, 2010; Smith, 1999). Although documentary linguistics is increasingly described as an effort to save languages, it has not traditionally held this aim, nor do all linguists agree (e.g.,

${ }_{5}^{5}$ Native American Languages. 


\section{WPEL Volume 30, Number 1}

Ladefoged 1992). According to Ives Goddard, who has produced a wealth of documentary materials on Indigenous American languages including Lenape, linguistics is "not just about rescuing some cute little language. It's learning about human intellectual capacity in general. The goal is to find the universal hardwired blueprint for language everyone is born with" (Maffly, 2012). In this pursuit, Indigenous languages are resources, but of a specific, objectified kind, and not necessarily for the speakers themselves.

Scholarship in education and language socialization has seen Indigenous languages as resources in the development of speakers' multilingual competencies (Eriks-Brophy \& Crago, 1994; Hornberger, 1988; Philips, 1972). The benefits of using Indigenous languages in education for literacy, content acquisition, and positive identity development have been illustrated in numerous settings around the world (Dekker \& Young, 2005; May \& Aikman, 2003; McCarty, 2003, 2008). Indigenous languages are also increasingly seen as basic human rights for their speakers (May, 2001; Skutnabb-Kangas \& Phillipson, 1994; United Nations Declaration on the Rights of Indigenous Peoples, 2007). Scholars from a range of disciplines have thus contributed to positive discourses about Indigenous languages, in particular when spoken by children entering formal schooling, and have encouraged their use.

Indigenous communities have also framed communicative practices in a variety of ways, with variation over time and among different groups (Hill, 2002; Kroskrity \& Field, 2009; Leap, 1981). Indigenous scholars and educators have drawn attention to the disadvantaged status of their languages and the discrimination faced by their speakers (e.g., Dick \& McCarty, 1996; Koohan Paik, 2006; National Indian Brotherhood, 1972), as well as the value that reclamation of their language has for identity affirmation and empowerment (e.g., Kipp, 2000; Watahomigie \& McCarty, 1996). As Shelley DePaul, the Lenape teacher whose class forms the basis of this study, writes, language is
the true personality of a culture. The language contains no misinterpre- tation, no bias, no imposition of foreign values... [It is] a portal to the accurate history of a people. This in itself is an adequate reason for the preservation of endangered languages. A more important reason, how- ever, is that the preservation of the language will restore to Native people so much that has been lost of their own culture (DePaul, 2008, para. 1).

Recognition that there are fewer and fewer people speaking Indigenous languages in North America and around the world has gained attention in the media and academia in recent decades (e.g. Grenoble \& Whaley, 2006; Hale et al., 1992; Harrison, 2007; Maffi, 2001; Nettle \& Romaine, 2000), where endangered languages are described as irreplaceable resources due to the unique knowledge and perspectives they encode. Language endangerment activists describe a bond between Indigenous languages, cultures, and the environments in which the languages evolve, using this as an argument for saving linguistic diversity, which they view as an important resource. Pressure from Indigenous organizations and scholars has also changed how the United States government talks about and acts towards Indigenous languages, resulting in the passage of the Native American Languages Act (1990, 1992; see Warhol 2011). The movement around language revitalization has thus increasingly brought new ways of talking about Indigenous 
languages into mainstream media, academia, and government, describing these languages as resources and rights.

As attempts to address language endangerment have increased in academia (e.g., Hinton \& Hale, 2001; Reyhner \& Lockard, 2009), several scholars have argued that current responses to this issue are guided by and/or produce discourses that do not achieve greater social justice for speakers of minoritized languages, and may continue to disadvantage them. These include the tendency of academic experts to represent languages as universally owned, hyperbolically valued commodities (Hill, 2002) or to focus on counting languages and speakers, which results in reductive notions of what counts as a language and who counts as a speaker (Moore et al., 2010; Muehlmann, 2012 illustrates community resistance to this kind of labeling). Purist language ideologies that resist language change may delegitimize and ultimately discourage younger speakers (Dorian, 1994; Goodfellow, 2003; Meek, 2010). Duchêne and Heller (2007) critique the essentializing and homogenizing effects of "discourses of endangerment" that parallel nationalist discourses, representing a language as an essential part of a specific identity and place. Costa (2013) suggests that revitalization discourses distract from more important socio-economic inequalities and may "lock peoples in an imagined past" (p. 318). Blommaert (2010) critiques connections made between language and place in this era of mobility and multiculturalism, warning that "a programme aimed at stimulating or promoting these local languages... ties the speakers of these languages to a place and reinforces the presumed fixed connection between people and their environment" (p. 45).

These scholars express concern with the ways that language, identity, place-and in particular the links between them-are constructed. They reject the constraining notions that they perceive as being reproduced though language revitalization discourses, and instead promote fluid notions of language, identity, and place. Who is responsible for certain discourses, how and by whom they are taken up, and what tangible impacts they might have on people are often unclear in scholarly discussions of language endangerment. It is clear, however, that there is a disjunction between theoretical positions held by the critical sociolinguists discussed above, and the discourses that circulate in language revitalization and reclamation settings. As Fishman (1991, pp. 381-388) pointed out, efforts to reverse language shift are likely to confound social theorists by drawing on ideas of ethnicity and, perhaps, essentialism that are commonly supposed to dissipate in our modern (and post-modern) era. In their ethnography of heritage language programs in the United Kingdom, Blackledge and Creese (2010) acknowledge this tension, stating that,

While it is certainly an oversimplification to treat certain languages as 'symbols' or 'carriers' of 'identity', we are obliged to take account of what people believe about their languages, listen to how they make use of their available linguistic resources, and consider the effects of their language use-even where we believe these 'languages' to be inventions (p. 31).

Writing from an Indigenous perspective, Gómez de García, Axelrod and Lachler (2009) discuss the flow of discourses between academic and Indigenous communities, noting that although "valorization of language as a treasure may not have originated within Indigenous communities, it resonates with the needs 


\section{WPEL Volume 30, Number 1}

and beliefs of community language activists, and they have worked to promote this view within the community" (p. 112). Leonard (2012) shows that language revitalization may produce both essentializing and empowering practices, with certain discourses employed as "strategic essentialism" (Spivak, 1996) in pursuit of locally-informed goals. He argues that positive outcomes occur when Indigenous people engage in language reclamation, as a process of recovering ownership of their languages and rejecting imposed or essentializing stereotypes. Work such as that inspired and documented by linguist Leanne Hinton (1994, 2002, 2013) over the past several decades demonstrates the positive outcomes for Indigenous language speakers, their families, and communities when they engage in long-term language reclamation efforts, at times affiliating with non-Indigenous institutions, linguistic departments, and linguists.

This study also examines a context where the categorical lines between Indigenous language activists, language learners and linguists are blurred. We illustrate how non-Lenape students in a university-based Indigenous language class negotiated identities as Lenape speakers and constructed language, identity and place in nuanced ways that are largely fluid and anti-essentializing. Moreover, participating in this Indigenous language reclamation context has led at least some participants to interrogate their notions of language, identity, and place, and the complex relationships between them, providing one possible antidote to essentialist discourses and practices. Although including Indigenous languages in formal higher education runs the risk of creating new forms of commodification and colonialism through institutional preferences for standardized and quantified ways of recognizing (or denying) teachers' and students' knowledge, in our study of this case such risks did not materialize.

\section{Ktahpihena: ${ }^{6}$ Situating the Present Study}

The study is based on an ethnographic case study of the Lenape language class taught in the Swarthmore College Linguistics department during spring 2012, as well as participant observation at several Lenape community events, ongoing conversations and interviews with the teacher, Shelley DePaul, interviews with several key supporters of the class, and with students from each year the class has been offered. DePaul and one of the program supporters are Lenape, one student is of North American Indigenous descent, and the rest of the students and other facilitators are of diverse non-Indigenous descent. We are three non-Indigenous researchers with experience working in and researching language revitalization and reclamation projects in the United States and elsewhere.

Data were collected by the second and third authors who learned about the program through a university announcement and requested permission to conduct research from the department chair, Ted Fernald, and DePaul, whose permission and encouragement we gratefully acknowledge. One or both of us attended one 75-minute class per week during a 14-week semester, or half the course sessions, and at the end of the semester conducted semi-structured interviews with five of the six students enrolled that year, as well as six students from previous years' classes. Interviews with DePaul and five professors and other facilitators of the class provided information on the administrative and political background of the

${ }^{6}$ We are here. 
course. We are also informed by on-going discussions with DePaul and the growing body of materials produced for the class by both DePaul and students, and are continuing to conduct observations and interviews as the program evolves. All fieldnotes, interview transcripts and memos were coded in Atlas.ti to identify both pre-identified and emergent themes. It is beyond the scope of this paper to present a full case study of this program or all of the themes identified in the data; here we briefly describe the background of the class, the participatory learning environment, and conclude with analysis of themes of language, identity and place.

\section{Ktalenixsi: ${ }^{7}$ Learning Lenape at Swarthmore College}

When Shelley DePaul, Language Specialist and Assistant Chief of the Lenape Nation of Pennsylvania, began researching and learning her heritage language in the 1980s, she and fellow community members knew only a few phrases (for the history of Lenape in Pennsylvania see Minderhout \& Franz, 2008; Seldin, Red Hawk Ruth \& DePaul, 2008). However, there are numerous historical and documentary sources available on the language spoken before the colonization of what is now eastern Pennsylvania, New Jersey, and southeastern New York (e.g., Blalock, Pearson \& Rementer, 1994; Goddard, 1978, 1979; Voegelin, 1945, 1946). Although these materials are difficult for someone without linguistics training to decipher, in the 1990s DePaul began using them to create less specialist materials to help other members of the Lenape Nation of Pennsylvania, a group incorporating several hundred members. ${ }^{8}$ Focusing on helping children achieve spoken communication, she emphasized songs and games that incorporated cultural knowledge, and was pleased to find that both children and adults were enjoying learning the language (DePaul, 2008).

After presenting her work at a 2008 conference on "Native American Languages in Crisis: Exploring the Interface Between Academia, Technology, and Smaller Native Language Communities" at the University of Pennsylvania, DePaul was approached by Ted Fernald, Professor of Linguistics at Swarthmore College, an elite private liberal arts college located in traditional Lenape territory. Fernald asked what could be done at Swarthmore to support tribal language efforts. Following her desire to promote learning and awareness of Lenape, DePaul took up the challenge and offered a class titled "Lenape Language Study" in spring 2009. She views the class as one piece of the continuing project of Lenape language promotion. DePaul notes that the class can be seen as a success story in interaction between academia and endangered languages, demonstrating not only that they can be mutually supportive but can also break down the conventional line between academics and endangered language speakers.

The Lenape language course has been taught in the Linguistics department every year from 2009 to 2012 and the college has committed to offering it every other year as of 2014. ${ }^{9}$ The course is credit-bearing and open to all students, without

\footnotetext{
${ }^{7}$ Let's speak Lenape.

8 Materials produced by Jim Rementer and Nora Thompson Dean of the Delaware Tribe of Indians were especially helpful, including the Lenape Talking Dictionary (www.talklenape.org).

9 Ongoing support by institutionally recognized authorities, in particular Ted Fernald, as well as Robert Preucel and Ann Dapice of the Native American Studies Center at the University of Pennsylvania has been crucial, as has funding from the college president, an NSF grant, and the University of Pennsylvania's Greenfield Intercultural Center.
} 


\section{WPEL Volume 30, Number 1}

prerequisites. Many Linguistics majors participate, as well as students majoring in Biology, Education, Math, and History, among others. The class size has been small, but this is not unusual at a small college that offers many specialized classes.

The class has evolved since 2009, and student interest has led DePaul to also offer an advanced class and advise students undertaking independent studies. The curriculum covered basic grammar and an extensive amount of vocabulary, as well as cultural and historical information. Two books developed by DePaul were used: Conversations in the Lenape Language, initially designed for tribal members, and an Advanced Supplements volume developed as worksheets during the first class, then compiled into a book (www.lenapenation.org/ lenapelanguage.html). The curriculum included student contributions from earlier years, including exercises, original stories, and verb conjugations. In a new addition in 2012, students read Mark Raymond Harrington's 1938 novel The Indians of New Jersey: Dickon Among the Lenapes, a fictional account of a shipwrecked European adopted by a band of Lenapes who learns Lenape practices (including language) but ultimately returns to live with Europeans. DePaul lauded the book's description of historical Lenape culture, and used it to introduce discussions of cultural practices, including interacting respectfully, learning by doing, and environmental stewardship, as well as discussions of the history of contact and treaties between Europeans and Lenape.

Class sessions followed a regular routine during the semester we observed. Sitting around a large table, students often took a short quiz on vocabulary and / or on Dickon Among the Lenapes. Next, they reviewed homework exercises, going in a circle to provide a translation or a sentence using a particular grammatical construction. DePaul offered corrections or alternative phrasings. These reviews, and indeed many other activities, sometimes prompted DePaul to discuss related topics, such as the challenges of standardization in both spoken and written language and the different dialects of Lenape.

After reviewing homework, they would turn to the day's lesson in Conversations in the Lenape Language and read through new vocabulary, a new grammar point, and a conversation from the book employing that vocabulary and grammar. They would consult the Advanced Supplements for additional grammar and exercises. Additional activities varied, including translation, talking about Lenape culture, conversation practice, or singing both traditional Lenape songs and songs such as "Head, Shoulders, Knees, and Toes" translated into Lenape. For special lessons, noted by several students as their most memorable classes, DePaul brought in artifacts including skins, furs, and lithic tools (e.g., stone drills and axe-heads).

The course ended with three major assignments: an in-class final, focused on translation and grammar; an original written story, with certain required grammar structures; and an open-ended final project. Many students chose to make pedagogical materials for their final projects, ranging from children's books and songs to YouTube videos to games, while others conducted more traditional linguistic projects such as analyzing aspects of grammar, interpreting old texts, and contributing to the growing verb dictionary. DePaul has uploaded students' contributions to the Lenape Nation of Pennsylvania's website and YouTube and uses them in tribal language programs, as well as in subsequent iterations of the college class. Several tribal members whom we met expressed their appreciation 
for the materials made by the students, noting that these materials help in their efforts to learn Lenape and/or teach it to their children.

Participatory relationships among students and between students and the teacher were commonly spoken of as highlights of the class. As exemplified in the following vignette, students were explicitly valued for their contributions to the class and the ongoing project of promoting Lenape.

Towards the end of the semester, on a spring day when everyone agrees to have class outdoors, Shelley reminds students that the class is an on-going experiment and that their input is important. She asks for feedback on the class and the learning materials. An open discussion follows, with everyone suggesting ways to improve the class for future students, including more conversation practice and more vocabulary related to their daily lives. Shelley mentions the challenge of talking about some things for which traditional words do not exist, such as airplanes, and the need to find ways of talking about these things all the same (Fieldnotes, 4/17/2012).

DePaul regularly acknowledged the contributions of students to the advancement of Lenape education, though their views on language, influenced by training in the field of linguistics, provided both advantages and challenges. In an interview she noted:

I listen. I take advice from the linguistics students, I like to hear their perspectives because they see it from a whole different way...We got in arguments all the time, you know, cultural versus linguistic view. But, no, they have been able to look at the language and say [...] something that I would never have noticed, not being a linguist (Interview, 4/11/2012).

Louise, a student who engaged in these debates, had a similar experience of positive collaboration:

I like to see it a certain way, and [Shelley] likes to see it a certain way, and that's OK. I mean, I think that's important, and it's important that the work the linguists do gets translated into an understandable way. It's been interesting learning to express my thoughts and ideas in a way that is not frustrating to someone who doesn't know what I'm talking about, and the importance of that (Interview, 4/19/2012).

The collaborative and participatory relationship between students and DePaul contributed to creating an environment where students not only learned an unfamiliar language but also took on new roles. Students participated as researchers, advocates, authors, and planners of orthography and language development. As another student noted, "I wanted to do my part as well. And [Shelley]...really treated us as equal. I think the reason why was because she looked at us, each individual, as one more person who would be working towards reviving this language" (Interview, 5/17/2012). Despite some prescriptive classroom activities like vocabulary tests and reciting verb conjugations, students were not treated as passive learners of fixed knowledge, but as valued members of a growing speech community. 


\title{
WPEL Volume 30, Number 1
}

Through participation in the course, students became aware of issues involved in language endangerment that were not necessarily on the syllabus. Amira, a linguistics major, appreciated gaining a more realistic understanding of the complexities involved in language reclamation:

It made me appreciate just how hard an endeavor it is to get people to speak the language or get people to be involved [...] Especially if you watch the movie The Linguists ${ }^{10}$ and you're like, 'oh, it all looks so cool and slick and fun' [...] so it was interesting to be behind the scenes, and maybe not get quite so much of the glamour but still have a more solid appreciation of how hard it is and how complex it is. (Interview 5/9/2012)

Issues around language standardization, dialect variation, and documentation; identity in relation to Lenape history and Indigenous-colonial relations; and place as evident in local plants and animals, sustainable subsistence practices, and the history of land treaties and territory loss, came up often throughout the class. The following sections examine ways of talking and acting about these themes of language, identity, and place as they emerged in interviews and observations.

\section{Ways of Talking (and Acting) About Language}

How Indigenous languages are taught, with what formats and goals, may influence how students view them. As discussed above, it is fairly common for Linguistics departments to present Indigenous languages as objects to be analyzed. It is rare to find a class where an Indigenous language is approached communicatively as a subject, with a goal of producing speakers. ${ }^{11}$ Although the Lenape class follows a format much like modern language classes, it is housed in Linguistics, and more unusual still, it is taught by a member of an Indigenous community.

The uncommon positioning of Lenape through this class—as a living language available to be spoken-gave some students new perspectives on Indigenous languages in general, and Lenape in particular. Mike, a linguistics major, commented:

\begin{abstract}
Shelley, the professor, would talk to us about how [...] in order to revitalize the language, to teach it to a younger generation, they actually had to [...] innovate quite a bit, in terms of creating some new words, establishing a solid written orthography, and how they've actually tried to put it into schools [...]. The little that I knew about endangered languages was more about how so many are going extinct, but not necessarily how the ones that have been revitalized or are in the process of being revitalized, how that actually goes about. (Interview, 6/3/2012)
\end{abstract}

Many students commented that this opportunity was unique, and that they knew little about Native American languages prior to taking the class.

\footnotetext{
10 A documentary following two linguists, one of them a professor at Swarthmore College, in their travels to document endangered languages in remote areas.

${ }^{11}$ Exceptions include long-standing Ojibwe programs at Universities of Michigan and Minnesota, and programs at University of Oklahoma, University of South Dakota, and University of Hawai'i, among others. Nonetheless, in the eastern United States, and in private universities, Indigenous language teaching programs are almost non-existent.
} 


\section{Learning Lenape in Pennsylvania}

Shortly after completing the class, Holly, a history major, discussed the symbolic value of learning an endangered language, drawing on comments DePaul made in class on the importance of language keepers dedicated to preserving linguistic knowledge:

[Shelley] said, as long as you remember just a few words-- so I try to teach my friends just a few words [...] Because she said that, even if there are just a few people who can remember a few words of it, that's important. (Interview, 5/2/2012).

The following semester Holly and a fellow student started a Lenape Language and Culture Club (LLCC). They described the club as follows in the charter document required by the university:

What is the mission of your group? What does your group work to achieve or accomplish? What values motivate that effort?

The mission of the LLCC is to contribute to the effort to preserve and revitalize the Lenape language and culture by creating a space for people to learn and practice their knowledge. The LLCC wants to spread both knowledge and appreciation for the Lenape language and culture. The LLCC is motivated by the notion of language keepers, people who, by knowing just a little of the language and passing it on to others, save the language and with it, the culture.

What are the opportunities or needs that your group exists to address?

The LLCC exists to address the need to educate Swarthmore students about Native American language and culture as well as the need to make an effort to preserve an endangered language.

Discussing the club several months after its founding, Holly and co-founder Owen described it as a space to practice and improve language skills, like the language tables where students practice modern languages. They noted that running the club helped them maintain their language skills and that they were pleased that several new students were active in the club and intended to take the Lenape course the next time it was offered. Their mission statement and comments illustrate their engagement with Lenape as a language to be learned, spoken and practiced (as any modern language), but also as a language of symbolic value.

Variation in language across time and space can be a challenge for endangered language education, as DePaul frequently discussed. She tried to use the dialect of the local region in her teaching, but also to respect current variation:

This is another issue: do we standardize the language? And people don't want to give up their ways of speaking. You become really attached to your language $[\ldots]$ There are so many, as you know, variants and dialects [...] You can't save them all [...] [but] I'm not going to go up to any Elder and say, you can't say mukwe for bear, 'cause that's how they pronounce it [...] and I'm not going to tell them not to. It's supposed to be màxkw, $\mathrm{OK}$, you say mukwe, I understand what you' re saying. (Interview, 11/4/2012) 


\title{
WPEL Volume 30, Number 1
}

DePaul's discussion illustrates the personal nature of language variation and her view that respecting variation is an important part of promoting Lenape language(s) —although she is not trying to "save" all varieties. She attempted to follow one variety in her class, but throughout the semester she informed students about variation and dialects.

In the context of this class, Lenape language thus has multiple accepted forms and performs multiple functions, including being a communicative practice as well as a channel for cultural survival.

\section{Ways of Talking (and Acting) About Identity}

\begin{abstract}
In April, Shelley gave each student a necklace with a wooden pendant carved to show the face of Meesink, a powerful Lenape symbol. "This is only given to friends of the Lenape. This is in thanks for learning the language. You are welcome in Lenape gatherings when you're wearing this," she told them. The following week, during a discussion of the future of Lenape classes at Swarthmore, Shelley continued on this theme: "You need to be proud of the fact that you are increasing the number of Lenape speakers in the state. That's a big deal. All of you are more fluent than most of the community. I've had almost 30 students and that makes me really happy" (Fieldnotes, 4/5/2012, 4/17/2012).
\end{abstract}

Several students wore their Meesink necklaces when we interviewed them, including some who had taken the class two years earlier. A year after she received her necklace Holly commented, "This goes everywhere with me. It came to Ireland with me," referring to her semester abroad. Another student explained that he was not wearing his because of the fear that he would lose it, but assured us that it was safe in his room (Fieldnotes, 5/14/13).

DePaul, as shown in the vignette above, explicitly included all students as members of the Lenape speaker community. Students, on the other hand, identified as Lenape speakers to varying degrees, especially those who were being interviewed several years after taking the class. One student commented, "I was a little surprised that we were actually learning conversational words. I was more expecting a study of the grammatical structure. But it was a happy surprise. I was glad that I learned how to actually speak it" (Interview, 5/2/2012; emphasis added). Other students said they felt "recruited" or "inducted" into a speaker community. Zack, an education and linguistics student noted, "when there's such a small speakership, there's such a small amount of people studying the language, it really does feel like a community" (Interview, 5/24/2012).

Conversations with DePaul and the students, in class and interviews, delineated two different communities related to the Lenape language. One was a community of Lenape speakers, which the students were part of; the second, the Lenape ethnic community, did not include the college students, none of whom were of Lenape descent. This boundary became particularly clear at an event that brought the students and the Lenape community together: a Lenape conference held at Swarthmore in 2010. Zack, who noted his struggles with the "identity politics" involved in learning Lenape, recalled voicing his worries about his relationship to the Lenape community at the conference: 


\section{Learning Lenape in Pennsylvania}

There was a point where I got up and I voiced this concern that I think a lot of us students shared of saying, 'This isn't my heritage language. If I were studying my heritage language it would be Yiddish or Romani or any of the heritage languages that I have, but I learn a lot and I gain a lot of social capital from studying the language, in terms of turning in papers, getting credits, getting a more enhanced knowledge of linguistics from the language', and so I essentially said, 'What can I do to give back? How can I, as a non-heritage speaker and a linguist, or a budding linguist I guess, how can I be responsible with my speakership to carry the language forward and not just be greedy with it by taking my own personal, taking the language for my own personal gain?' Because with a small language like that it is really key, I think, that you have to give back.

(Interview, 5/24/2012)

This was a memorable moment for other students too, including Louise, who also attended the conference and summarized this moment in an interview. Both students have continued to grapple with this as an ongoing issue.

These lines drawn between identity and language abilities also made students wonder about the limits of their engagement with the language, for instance if they could move from being students to being teachers. Louise voiced ongoing concerns:

I was thinking, wouldn't it be interesting to do a class on Lenape culture and the kids could use that as their American history requirement. But, I'm not in that culture. Do I have the right to be teaching it? ... So I talk to Shelley about things like that. And I definitely want the permission of at least some of the Elders to be able to go and do that. But that's not something you would ordinarily have a problem with, with a non-endangered language, or culture (Interview, 4/19/2012).

Louise worried that teaching the language would cross a boundary of appropriate engagement with Lenape. She and several other students expressed a feeling that learning Lenape was different from learning other languages due to its status as a small, minoritized language and also because it was not the students' heritage language.

No student claimed Lenape identity affiliation, and a student without Lenape heritage would have been strongly discouraged from doing so due to DePaul's complaints about "New Agers" co-opting Indigenous identity. As DePaul put it in an interview, "nobody has the right to declare themselves an authority if they're not Lenape or they're not Indigenous" $(4 / 11 / 2012)$. However, as illustrated in the example of the Lenape Language and Culture Club, some students felt comfortable taking up roles as non-Lenape people acting as language keepers, a human archive to maintain knowledge of the language - an endeavor supported (but not initiated) by DePaul. In general, teaching and learning in and around the Lenape class occurred in collaborative ways with DePaul encouraging students' participation in linguistic and pedagogical decisions. At the same time, ethnic affiliation remained distinct from linguistic competence, and an index of ultimate authority in language issues. 


\section{Ways of Talking (and Acting) About Place}

As the weather warmed up during the spring semester, class was often held outside, in a circle on the lawn. Every time class took place outside Shelley told the students that she was always happy to be outside instead of in a building. One morning, Shelley held up the beginning of formal class to look for plantains, a plant with medicinal properties that commonly grows as a weed. In the end, she couldn't find one and returned, explaining that plantains are useful for many medicinal purposes (Fieldnotes, 4/10/2012).

The importance of place appeared in multiple ways throughout the class and in students' discussions of what they had learned from the course. The natural world was salient in vocabulary and culture discussions. One student remarked that a challenge in learning vocabulary was that she had to memorize varieties of birds and plants that she did not previously know the names of in English, let alone Lenape. Linguistics major Myles recalled:

The writing we did in Lenape was often in this sort of fantasyland [...] generated partly by the vocabulary we had. It's very naturalistic, and 'so and so was walking through the woods, and they ran into an animal, and the animal said this...' (Interview, 5/17/2012).

In addition to vocabulary that emphasized the natural world, class discussions about culture often emphasized Lenape connections to the land, including DePaul's involvement in lifeguarding on the Delaware River and harvesting seasonal foods, or descriptions of ceremonies linked to planting and harvesting.

Some students expressed a new understanding of their relationship to the place where they lived as a result of the class. As Owen described,

Definitely if you work really hard at it you'll get a lot out of it. Like not only in learning the language [...] you'll understand more about the culture and have a new perspective [...] Like when I'm walking around on the ground or something, I'll have more of an air of respect. Like, oh, grass. Not just like, grass, whatever. Definitely it changes the way you view where you're living. (Interview, 5/2/2012)

Several students reflected that they were now aware of the historical Lenape ownership of the land that the College was on, and had enjoyed learning etymologies of local place names during the class.

This knowledge was not limited to Lenape land but extended to that of other tribes as well. Louise noted:

It's funny how learning Lenape has affected my view of other things, like, I never was interested in American history at all, and all of a sudden, I want to know which tribes were where, what happened [...] I don't know much yet, but I'm definitely interested, and have a sense of what some of the other tribes were in this region, since I have something to compare it with. I know where the Lenape territory is. So when we're driving up, I'm like, 'hey, we're in Lenape territory now' and when we 
get further north, I'll go, 'oh, we're in Mohawk territory now' (Interview, 4/19/2012).

The pre-colonial history of North America receives little attention at any level of education in the United States, so learning about Lenape history represented an unusual opportunity for students. Students heard about the lack of recognized Lenape presence in Pennsylvania due to the Walking Treaty of 1737 and the Indian Removal Act of 1830, resulting in the only federally recognized Lenape land in the United States being located in Oklahoma and Wisconsin.

While the natural environment was a stronger theme than political history throughout the class, the incorporation of issues of place raised many students' awareness of the contested history, as well as flora and fauna, of their current place of residence.

\section{Ktakenutamena ${ }^{12}$ : Negotiating Language, Identity, and Place}

In modern language study there is generally little attention to the political and historical processes through which languages have come to be standardized and affiliated with a place, culture and population. In contrast, these issues are almost unavoidable in endangered language study. It is not about counting languages or speakers, but rather about asking: What counts as the language, who counts as a legitimate speaker, and who should have power to control or certify these things? What to make of historical and ongoing changes in the places where languages are spoken and the number of people speaking them, changes usually beyond the control of the speakers themselves? In addition to actual language competence, a more nuanced awareness of the sociopolitically charged nature of language use, as well as attention to the fluidity among language, place, and identity, are thus possible outcomes of endangered language education. These outcomes are not readily countable, but provide exponential benefits for the participants engaged in such an education context.

As we have seen above, students of minoritized, endangered languages may find themselves face to face with the conflict and politics inherent in the standardization and formalization of any language, the authenticity of identity and the right to speak, or the contested histories of Indigenous peoples in colonized territories. In this case, the Lenape class provided a space where these potential conflicts around language, identity, and place were negotiated amicably. DePaul and Louise both talked about the challenges and benefits of having different views on language norms, with the students' views based in formal linguistic training and DePaul's in considerations for the learnability and acceptability of the language among members of the Lenape Nation of Pennsylvania. DePaul invited students to be proud they are increasing the numbers of Lenape speakers even while being clear they are not thereby ethnically Lenape, an identity politics students like Zack took seriously. The land on which the class took place, both inside and outside the college buildings, served as an entry point for students to acquire new understandings of Lenape - and Native Americanhistory and cultural practices tied to the land.

Due to the diffused nature of linguistic authority instilled by Shelley's intentional pedagogical practices but also in a fundamental way by the college's

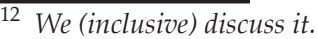




\section{WPEL Volume 30, Number 1}

recognition of her autonomy and authority in inviting her to teach the course, many students were motivated in this participatory educational space to engage with the language in enthusiastic and personal ways, taking up roles as researchers, writers, speakers, and language keepers, as well as learners. This participatory approach to including an endangered language in formal higher education allowed "budding linguists" to actively participate in language reclamation, providing research and resources that are in turn welcomed by a community whose cultural and linguistic presence has been largely removed and erased across generations of colonial and post-colonial processes. Although not all communities would choose to invite non-members to learn their language or desire to make their language more prominent in colonial-origin institutions such as universities, this case illustrates the potential benefits of this approach for those who might find it an appropriate way to achieve community goals. As minoritized languages continue to be the subject of academic and social projects, we argue that participatory, reflective and collaborative educational programs hold great potential to support the goals of a variety of social actors, while reclaiming and validating local ways of speaking. As Helen, the student whose comments opened this paper, went on to say:

I think that a language course of an endangered language is great. It just gets you to think about it. Plus there's this, you know, endangered languages not being learned-- there are certainly impacts with the community, depending on the group, with outsiders learning the language [...] If there are people showing interest in this language and learning, there's the hope that that can help sustain the language itself. Or at least help push things in that direction (Interview, 6/8/2012).

\section{Acknowledgments}

We gratefully acknowledge the input and support of Shelley DePaul and the Lenape Nation of Pennsylvania, Ted Fernald and the Department of Linguistics at Swarthmore College, and the participants in the Lenape program. We are also grateful for comments from participants at the PennGSE Language and Literacy in Education Proseminar where we presented an earlier version of this paper. This research was funded in part by summer research grants from the University of Pennsylvania Graduate School of Education. A final version of this paper will appear in a forthcoming issue of Journal of Language, Identity, and Education.

Nancy H. Hornberger is Professor of Education and Chair of Educational Linguistics at the University of Pennsylvania, USA. Her research interests include anthropology of education, bilingualism and biliteracy, linguistic anthropology, language policy and Indigenous language revitalization.

Haley De Korne is a PhD candidate in Educational Linguistics at the University of Pennsylvania. She researches and participates in multilingual education programs and politics, with a special focus on the inclusion of marginalized and endangered language groups.

Miranda Weinberg is a PhD candidate in Educational Linguistics and Anthropology at the University of Pennsylvania. Her research interests include language planning and policy, language shift and language revitalization, especially in Nepal and the United States. She can be reached at mirandaw@gse.upenn.edu. 


\section{References}

Amery, R. (1995). It's ours to keep and call our own: Reclamation of the Nunga languages in the Adelaide region, South Australia. International Journal of the Sociology of Language, 113, 63-82.

Battiste, M., \& Henderson, J. S. Y. (2000). Protecting Indigenous knowledge and heritage: A Global Challenge. Saskatoon, Saskatchewan, Canada: Purich.

Blackledge, A., \& Creese, A. (2010). Multilingualism: A critical perspective. London, England: Continuum.

Blalock, L., Pearson, B., \& Rementer, J. (1994). The Delaware language. Bartlesville, OK: Delaware Tribe of Indians.

Blommaert, J. (2010). The sociolinguistics of globalisation. Cambridge, England: Cambridge University Press.

Boas, F. (1911). Handbook of American Indian languages. Washington, DC: US Government Printing Office.

Calvet, L. J. (1974). Linguistique et colonialisme: Petit traite de glottophagie. Paris, France: Payot.

Costa, J. (2013). Language endangerment and revitalization as regimes of truth: Shifting terminology to shift perspective. Journal of Multilingual and Multicultural Development, 34(3), 317-331.

Crawford, J. (2007) Seven hypotheses on language loss: Causes and cures. In G. Cantoni, (Ed.), Stabilizing Indigenous languages (pp. 45-60). Flagstaff: Northern Arizona University.

Dekker, D., \& Young, C. (2005). Bridging the gap: The development of the appropriate education strategies for the minority language communities in the Philippines. Current Issues in Language Planning, 6(2), 182-199.

DePaul, S. (2008, May). Relearning Lenape: A holistic approach. Paper presented at conference on Endangered Languages: Exploring the Interface Between Academia and Native American Communities, Philadelphia, PA.

Dick, G. S., \& McCarty, T. L. (1996). Reclaiming Navajo: Language renewal in an American Indian community school. In N. H. Hornberger (Ed.), Indigenous literacies in the Americas: Language planning from the bottom up (pp. 69-94). Berlin, Germany: Mouton de Gruyter.

Dobrin, L., Austin, P., \& Nathan, D. (2007). Dying to be counted: Commodification of endangered languages in documentary linguistics. In P. Austin, O. Bond, \& D. Nathan (Eds.), Proceedings of the Conference on Language Documentation and Linguistic Theory (pp. 59-68). Berlin, Germany: Springer.

Dorian, N. C. (1994). Purism vs. compromise in language revitalization and language revival. Language in Society, 23(4), 479-494.

Duchêne, A., \& Heller, M. (Eds.) (2007). Discourses of endangerment: Ideology and interest in the defense of languages. London, England: Continuum.

Eriks-Brophy, A., \& Crago, M. (1994). Transforming classroom discourse: An Inuit example. Language and Education, 8, 105-122.

Fishman, J. (1991). Reversing language shift: Theoretical and empirical foundations of assistance to threatened languages. Bristol, England: Multilingual Matters.

Goddard, I. (1978). Delaware. In B. Trigger (Ed.), Handbook of North American Indians, Volume 15: Northeast (pp. 213-239). Washington, DC: Smithsonian Institution Press. 


\section{WPEL Volume 30, Number 1}

Goddard, I. (1979). Delaware verbal morphology. New York, NY: Garland.

Gómez de García, J., Axelrod, M., \& Lachler, J. (2009). English is the dead language: Native perspectives on bilingualism. In P. V. Kroskrity \& M. C. Field (Eds.), Native American language ideologies: Beliefs, practices, and struggles in Indian country (pp. 99-122). Tucson: University of Arizona Press.

Goodfellow, A. (2003). The development of "new" languages in Native American communities. American Indian Culture and Research Journal, 27, 41-59.

Grenoble, L. \& Whaley, L. (2006). Saving languages: An introduction to language revitalization. Cambridge, England: Cambridge University Press.

Hale, K., Krauss, M., Watahomigie, L. J., Yamamoto, A. Y., Craig, C., Jeanne, L. M., \& England, N. C. (1992). Endangered languages. Language, 68(1), 1-42.

Harrington, M. R. (1938). The Indians of New Jersey: Dickon among the Lenapes. New Brunswick, NJ: Rutgers University Press.

Harrison, K. D. (2007). When languages die: The extinction of the world's languages and the erosion of human knowledge. Oxford, England: Oxford University Press.

Hill, J. H. (2002). "Expert rhetorics" in advocacy for endangered languages: Who is listening, and what do they hear? Journal of Linguistic Anthropology, 12(2), 119-133.

Hinton, L. (1994). Flutes of fire: Essays on California Indian languages. Berkeley, CA: Heyday Books.

Hinton, L. (2002). How to keep your language alive: A commonsense approach to oneon-one language learning. Berkeley, CA: Heyday Books.

Hinton, L. (Ed.) (2013). Bringing our languages home: Language revitalization for families. Berkeley, CA: Heyday Books.

Hinton, L., \& Hale, K. L. (Eds.) (2001). The green book of language revitalization in practice. San Diego, CA: Academic Press.

Hohepa, M. K. (2006). Biliterate practices in the home: Supporting indigenous language regeneration. Journal of Language, Identity, and Education, 5(4), 293-301.

Hornberger, N. H. (1988). Bilingual education and language maintenance: A southern Peruvian Quechua case. Berlin, Germany: Mouton de Gruyter.

Hornberger, N. H. (Ed.) (2008). Can schools save Indigenous languages? New York, NY: Palgrave Macmillan.

Hornberger, N. H., \& King, K. A. (1996). Bringing the language forward: Schoolbased initiatives for Quechua language revitalization in Ecuador and Bolivia. In N. H. Hornberger (Ed.), Indigenous literacies in the Americas: Language planning from the bottom up (pp. 299-319). Berlin, Germany: Mouton de Gruyter.

Kipp, D. (2000). Encouragement, guidance and lessons learned for Native language activists developing their own Tribal language programs. Browning, MT: Piegan Institute.

Koohan Paik, E. (2006). The fall and rise of a native language. In J. Mander \& V. Tauli-Corpuz (Eds.), Indigenous peoples' resistance to economic globalization. San Francisco, CA: International Forum on Globalization.

Kroskrity, P. V., \& Field, M. C. (Eds.) (2009). Native American language ideologies: Beliefs, practices, and struggles in Indian country. Tucson: University of Arizona Press. 


\section{Learning Lenape in Pennsylvania}

Ladefoged, P. (1992). Another view of endangered languages. Language, 68(4), 809-811.

Leap, W. L. (1981). American Indian language maintenance. Annual Review of Anthropology, 10, 209-236.

Leonard, W. Y. (2012). Framing language reclamation programmes for everybody's empowerment. Gender and Language, 6(2), 339-367.

Maffi, L. (2001). On biocultural diversity: Linking language, knowledge, and the environment. Washington, DC: Smithsonian Institution Press.

Maffly, B. (2012, September 18). University of Utah shifts focus on indigenous languages. The Salt Lake Tribune. Retrieved from http:/ / www.sltrib.com

May, S. (2001). Language and minority rights: Ethnicity, nationalism and the politics of language. London, England: Longman.

May, S., \& Aikman, S. (2003). Indigenous Education: Addressing current issues and developments. Comparative Education, 39(2), 139-145.

McCarty, T. L. (2003). Revitalising indigenous languages in homogenising times. Comparative education, 39(2), 147-163.

McCarty, T. L. (2008). Native American languages as heritage mother tongues. Language, Culture and Curriculum, 21(3), 201-225.

McCarty, T. (2013). Language planning and policy in Native America: History, theory, praxis. Bristol, England: Multilingual Matters.

Meek, B. A. (2010). We are our language: An ethnography of language revitalization in a Northern Athabaskan community. Tucson: University of Arizona Press.

Minderhout, D. J., \& Franz, A. T. (2008). Invisible Indians: Native Americans in Pennsylvania. Amherst, NY: Cambria Press.

Moore, R., Pietikäinen, S., \& Blommaert, J. (2010). Counting the losses: Numbers as the language of language endangerment. Sociolinguistic Studies, 4(1), $1-26$.

Muehlmann, S. (2012). Von Humboldt's parrot and the countdown of last speakers in the Colorado Delta. Language \& Communication, 32(2), 160-168.

National Indian Brotherhood (1972). Indian control of Indian education. Ottawa, Ontario, Canada: Author.

Native American Languages Act of 1990, United States Public law No. 101-477, 25 U.S.C. 2901-2906.

Native American Languages Act of 1992, United States Public law No. 102-524, 42 U.S.C. 2991-2992d.

Nettle, D., \& Romaine, S. (2000). Vanishing voices: The extinction of the world's languages. Oxford, England: Oxford University Press.

Philips, S. (1972). Participant structures and communicative competence: Warm Springs children in community and classroom. In C. B. Cazden, V. P. John, \& D. Hymes (Eds.), Functions of language in the classroom (pp. 370394). New York, NY: Teachers College Press.

Reyhner, J. A., \& Eder, J. M. O. (2006). American Indian education: A history. Norman: University of Oklahoma Press.

Reyhner, J., \& Lockard, L. (Eds.) (2009). Indigenous language revitalization: encouragement, guidance \& lessons learned. Flagstaff: Northern Arizona University.

Romaine, S. (2006). Planning for the survival of linguistic diversity. Language Policy, 5(4), 443-475. 


\section{WPEL Volume 30, Number 1}

Ruíz, R. (1984). Orientations in language planning. NABE Journal, 8(2), 15-34.

Sapir, E. (1912). Language and environment. American Anthropologist, 14(2), 226242.

Seldin, A., Red Hawk Ruth, R., \& DePaul, S. (2008). In the time of the Fourth Crow: The Reemergence of the Lenape of Pennsylvania. Cultural Survival Quarterly, 32(3), 32-35.

Skutnabb-Kangas, T., \& Phillipson, R. (Eds.) (1994). Linguistic human rights:

Overcoming linguistic discrimination. Berlin, Germany: Mouton de Gruyter.

Smith, L. T. (1999). Decolonising methodologies: Research and Indigenous people. London, England: Zed Books.

Smithsonian Institute Recovering Voices Initiative (2009). http: / / anthropology. si.edu/recovering_voices/index.htm

Spivak, G. C. (1996). Subaltern studies: Deconstructing historiography. In D. Landry \& G. MacLean (Eds.), Selected works of Gayatri Chakravorty Spivak (pp. 203-235). London, England: Routledge.

United Nations Declaration on the Rights of Indigenous Peoples (2007). Paris, France: UNESCO. Retrieved from http:/ / www.un.org/esa/socdev/ unpfii/en/drip.html.

US Congress (1868). Commissioner of Indian Affairs for the Year 1868, Annual Report (pp. 26-50). Washington, DC: Government Printing Office. Retrieved October 12, 2012 from http: / / eweb.furman.edu/ benson/ docs / peace.htm

Voegelin, C. F. (1945). Delaware texts. International Journal of American Linguistics, $11,105-119$.

Voegelin, C. F. (1946). Delaware, an Eastern Algonquian language. In H. Hoijer (Ed.), Linguistic structures of Native America (pp. 130-157). New York, NY: Viking Fund.

Warhol, L. (2011). Native American language education as policy-in-practice: An interpretative policy analysis of the Native American Languages Act of 1990/1992. International Journal of Bilingual Education and Bilingualism, 14(3), 279-299.

Watahomigie, L., \& McCarty, T. (1996). Literacy for what? Hualapai literacy and language maintenance. In N. H. Hornberger (Ed.), Indigenous literacies in the Americas: Language planning from the bottom up (pp. 69-94). Berlin, Germany: Mouton de Gruyter. 